\title{
MICROPROPAGAÇ̃̃O DE DUAS ESPÉCIES FRUTÍFERAS, EM MEIO DE CULTURA DSD1, MODIFICADO COM FONTES DE BORO E ZINCO
}

\author{
Micropropagation of two fruit tree species on dsd1 culture medium \\ modified with boric acid and zinc sulfate
}

\author{
Fabíola Villa', Moacir Pasqual' ${ }^{2}$, Franscinely Aparecida de Assis ${ }^{3}$, \\ Gleice Aparecida de Assis ${ }^{4}$, Danielle Zampiere Arce Zárraga ${ }^{5}$
}

\begin{abstract}
RESUMO
A micropropagação de frutíferas de clima temperado pode gerar plantas livres de vírus e num curto espaço de tempo. Objetivando-se aprimorar técnicas de propagação in vitro de amoreira-preta e videira, foram testadas diferentes concentrações de boro e zinco, adicionados ao meio de cultivo. O meio foi constituído de sais DSD1, acrescido de $30 \mathrm{~g} \mathrm{~L}^{-1}$ de sacarose e $7 \mathrm{~g} \mathrm{~L}^{-1}$ de ágar, e o pH ajustado para 6,4 antes da autoclavagem a $121^{\circ} \mathrm{C}$ e $1 \mathrm{~atm}$ por 20 minutos. Os tratamentos consistiram de segmentos nodais de amoreira-preta cv. Tupy, do porta-enxerto de videira 'Kobber' e de concentrações de ácido bórico ( $0 ; 1,0 ; 2,0$ e 4,0 $\left.\mathrm{mg} \mathrm{L}^{-1}\right)$ e sulfato de zinco hidratado $\left(0 ; 1,0 ; 2,0\right.$ e 4,0 $\left.\mathrm{mg} \mathrm{L}^{-1}\right)$, em todas as combinações possíveis. Segmentos nodais de plantas preestabelecidas in vitro foram excisados e inoculados em tubo de ensaio, contendo $15 \mathrm{~mL}$ do meio de cultura. Posteriormente, os tubos de ensaio foram transferidos para sala de crescimento a $27 \pm 1^{\circ} \mathrm{C}$, irradiância de $35 \mathrm{mmol} \cdot \mathrm{m}^{-2} \cdot \mathrm{s}^{-1} \mathrm{e}$ fotoperíodo de 16 horas. O delineamento experimental utilizado foi inteiramente casualisado, utilizando-se 4 repetições com 12 explantes cada. Após 70 dias de cultivo in vitro verificou-se que, melhores resultados na micropropagação de amoreira-preta cv. Tupy (Rubus sp.) foram obtidos na ausência de ácido bórico e sulfato de zinco hidratado em meio de cultura DSD1. Com 4,0 $\mathrm{mg} \mathrm{L}^{-1}$ de ácido bórico adicionado ao meio, verificou-se maior número de folhas e comprimento de raízes do porta-enxerto de videira 'Kobber' (Vitis sp.).
\end{abstract}

Termos para indexação: Rubus sp.; Vitis sp., micropropagação, ácido bórico, sulfato de zinco.

\begin{abstract}
The micropropagation of temperate fruit trees may generate virus-free plants with the additional advantage of a shorter period of time compared to the traditional culture. Aiming to improve the in vitro propagation of blackberry and grapevine, different boron and zinc concentrations added to the culture medium were tested. The culture medium was constituted of DSD1 salts, added of $30 \mathrm{~g} \mathrm{~L}^{-1}$ sucrose and $7 \mathrm{~g} \mathrm{~L}^{-1}$ agar, and the $\mathrm{pH}$ adjusted to 6.4 before the sterilization at $121^{\circ} \mathrm{C}$ and $1 \mathrm{~atm}$ per 20 minutes. The treatments consisted of blackberry plants cv. Tupy, the grapevine rootstock 'Kobber' and concentrations of boric acid $\left(0 ; 1.0 ; 2.0\right.$, and $\left.4.0 \mathrm{mg} \mathrm{L}^{-1}\right)$ and zinc sulfate $\left(0 ; 1.0 ; 2.0\right.$, and $\left.4.0 \mathrm{mg} \mathrm{L}^{-1}\right)$, mixed in all possible combinations. Nodal segments of in vitro cultivated plants were excised and inoculated in tubes with $15 \mathrm{~mL}$ culture medium. After that, the tubes were transferred to a growth room at $27 \pm 1^{\circ} \mathrm{C}$, irradiance of 35 mol. $\mathrm{m}^{-2} \cdot \mathrm{s}^{-1}$ and photoperiod of 16 hours. The experiment was arranged in a completely randomized design, using four replications with 12 plants each. After 70 days of in vitro cultivation it was verified that the best results for the micropropagation of blackberry cv. Tupy (Rubus sp.) were obtained in the absence of boric acid and zinc sulfate mixed in the DSD1culture medium. With $4.0 \mathrm{mg} \mathrm{L}^{-1}$ boric acid added to the culture medium higher number of leaves and length of roots of the grapevine rootstock 'Kobber' (Vitis sp.) was observed.
\end{abstract}

Index terms: Rubus sp., Vitis sp., micropropagation, boric acid, zinc sulfate.

(Recebido em 17 de outubro de 2006 e aprovado em 3 de março de 2008)

\section{INTRODUÇÃO}

A fruticultura de clima temperado apresenta grande importância no contexto da produção mundial de frutas. Algumas das frutas produzidas em maior volume em todo o mundo, tais como a macieira e a videira, são de espécies pertencentes a essa classe. Além disso, essas espécies são cultivadas com maior intensidade nas regiões de maior consumo de frutas, como os países desenvolvidos do Hemisfério Norte (CHALFUN et al., 1998; NORBERTO et al., 2008).

No Brasil, a amoreira-preta (Rubus sp.) vem sendo cultivada por pequenos produtores do Rio Grande do Sul (principal produtor brasileiro), Santa Catarina e Paraná, objetivando a exportação dos frutos. O sul de Minas Gerais

\footnotetext{
${ }^{1}$ Pós-Doutoranda em Fitotecnia - EPAMIG - Rua Washington Alvarenga Viglione, s/n - Bairro Vargedo - 35517-000 - Maria da Fé, MG - fvilla2003@libero.it ${ }^{2}$ Doutor, Professor Adjunto - Departamento de Agricultura/DAG - Universidade Federal de Lavras/UFLA - Cx. P. 3037 - $37200-000$ - Lavras, MG mpasqual@ufla.br

${ }^{3}$ Mestranda em Entomologia - Departamento de Entomologia/DEN - Universidade Federal de Lavras/UFLA - Cx. P. 3037 - $37200-000$ - Lavras, MG franscinely@agronomia.ufla.br

${ }^{4}$ Mestranda em Fitotecnia - Departamento de Agricultura/DAG - Universidade Federal de Lavras/UFLA - Cx. P. 3037 - $37200-000$ - Lavras, MG gleice_ufla@yahoo.com.br

${ }^{5}$ Bióloga - Departamento de Agricultura/DAG - Universidade Federal de Lavras/UFLA - Cx. P. 3037 - 37200-000 - Lavras, MG - danitucha@hotmail.com
} 
tem apresentado elevado potencial para essa fruta, destacando-se o município de Caldas. A sua propagação se faz através de estacas de raízes, ou ainda por brotos (rebentos), originados de plantas cultivadas e estacas herbáceas (ANTUNES et al., 2004). Além desses, com a micropropagação, é possível obter plantas livres de vírus, geneticamente uniformes e em curto espaço de tempo, sendo assim uma alternativa viável (PEIXOTO \& PASQUAL, 1996; SKIRVIN et al., 1981).

A cultura da videira (Vitis spp.), pela sua extensa área plantada no Brasil e pelo seu potencial de utilização como matéria-prima para indústrias de vinhos, sucos, geléias, passas, vinagres, e para consumo in natura, constitui uma importante fruteira de clima temperado, ocupando o terceiro lugar quanto ao valor de produção.

Devido à grande variabilidade genética e à maior dificuldade de diferenciação e crescimento in vitro, a micropropagação de espécies lenhosas requer estudos mais específicos e desenvolvimento de metodologias que atendam às exigências do explante. Os meios nutritivos utilizados na micropropagação fornecem substâncias essenciais para o crescimento dos tecidos e controlam, em grande parte, o padrão de desenvolvimento in vitro (CALDAS et al., 1998). Embora o meio MS (MURASHIGE \& SKOOG, 1962) tenha favorecido o crescimento e desenvolvimento de várias espécies, a utilização de composições mais diluídas, como o meio DSD1 (SILVA \& DOAZAN, 1995), para algumas espécies lenhosas, como é o caso da videira, tem fornecido melhores resultados.

Existe grande variedade de meios para micropropagação. Entretanto, a maioria das descrições de preparos de meios alternativos não demonstram de maneira comparativa se o novo meio é ou não melhor que o outro do qual foi originado. Esse deve ser selecionado em função da espécie e tipo de cultivo que está sendo efetivado (PASQUAL et al., 1997). Várias mudanças de padrão foram propostas na tentativa de otimizar o crescimento in vitro. Essas visam principalmente a redução ou incremento de alguns componentes, como por exemplo os micronutrientes, que podem promover melhor crescimento em tecidos vegetais (VILLA et al.2008).

$\mathrm{O}$ boro é encontrado no solo sob a forma de ácido bórico e é o composto usado como fonte do elemento, em cultura de tecidos (PASQUAL, 2001). Esse é o único micronutriente que não atende ao critério direto de essencialidade, mas satisfaz o critério indireto. A maior prova da sua essencialidade consiste em que, nos solos das regiões tropicais, é o nutriente que mais promove deficiências nas culturas. O sintoma da deficiência do boro em plantas é a paralisação do crescimento dos meristemas apicais (FAQUIN, 2001).
O zinco é um elemento muito importante, pois, é responsável direto pela síntese do triptofano, um precursor da auxina (ácido indolacético), e indireto pela síntese de proteína. A ausência do triptofano estimula a formação de calosidade nos tecidos vegetais (KUPPER et al., 1979). A principal função do zinco no metabolismo vegetal é como componente ativador enzimático, e está envolvido no metabolismo de auxinas, em particular no ácido indolacético (AIA) (FAQUIN, 2001). Os sintomas mais típicos da carência do elemento consistem no encurtamento dos internódios e na produção de folhas pequenas cloróticas e lanceoladas (BROADLEY et al., 2007).

Objetivou-se, neste trabalho, verificar o desenvolvimento in vitro dos explantes de duas espécies frutíferas em meio DSD1, com diferentes concentrações de ácido bórico e sulfato de zinco.

\section{MATERIAL E MÉTODOS}

Segmentos nodais de amoreira-preta (Rubus spp.), com cerca de $2 \mathrm{~cm}$ de comprimento, oriundos de brotações preestabelecidas in vitro foram excisados e introduzidos em tubos de ensaio, contendo $15 \mathrm{~mL}$ do meio de cultura DSD1 modificado (SILVA \& DOAZAN, 1995). O experimento consistiu de explantes de amoreira-preta (Rubus sp.) cv. Tupy e do porta-enxerto de videira (Vitis spp.) 'Kobber', com quatro diferentes concentrações de ácido bórico ( 0 ; 1,$0 ; 2,0$ e $4,0 \mathrm{mg} \mathrm{L}^{-1}$ ) e quatro de sulfato de zinco hidratado $\left(0 ; 1,0 ; 2,0\right.$ e $\left.4,0 \mathrm{mg} \mathrm{L}^{-1}\right)$, em todas as combinações possíveis, adicionadas ao meio de cultura.

Os meios de cultivo foram acrescidos de $20 \mathrm{~g} \mathrm{~L}^{-1}$ de sacarose, solidificados com $7 \mathrm{~g} \mathrm{~L}^{-1}$ de ágar e o $\mathrm{pH}$ ajustado para 6,4 , antes da autoclavagem a $121^{\circ} \mathrm{C}$ e 1 atm por 20 minutos. Posteriormente à inoculação, os tubos de ensaio foram transferidos para sala de crescimento a $25 \pm 2{ }^{\circ} \mathrm{C}$, irradiância de $35 \mathrm{mmol} . \mathrm{m}^{-2}$. $\mathrm{s}^{-1} \mathrm{e}$ fotoperíodo de 16 horas diárias, permanecendo nessas condições por 70 dias. $\mathrm{O}$ delineamento experimental utilizado foi inteiramente casualisado, utilizando-se quatro repetições com doze plântulas por tratamento.

Foram avaliados os números de folhas e de raízes, comprimento da parte aérea e das raízes e peso da matéria fresca da parte aérea. Os dados foram analisados através do software Sisvar (FERREIRA, 2000), utilizando regressão polinomial para as variáveis.

\section{RESULTADOS E DISCUSSÃO}

Os resultados da análise de variância para as características avaliadas estão apresentados nas Tabelas 1 e 2 . No experimento com o porta-enxerto de videira, utilizando o teste $\mathrm{F}$, ao nível de $5 \%$ de probabilidade, 
observou-se significância do micronutriente boro apenas para número de folhas e comprimento da maior raiz do porta-enxerto de videira. Não houve interação significativa para o comprimento da parte aérea, peso da matéria fresca da parte aérea e número de raízes em relação à mudança da concentração dos micronutrientes do meio de cultura DSD1.

Em todos os tratamentos que continham a fonte de zinco foi verificada a presença de calos na base dos explantes utilizados. Isso se deve ao fato desse elemento ser diretamente responsável pela síntese do triptofano, um precursor da auxina (ácido indolacético), e indireto pela síntese de proteína. A ausência do triptofano estimula a calogênese nos tecidos vegetais (KUPPER et al., 1979). A principal função do zinco no metabolismo vegetal é como componente ativador enzimático, e está envolvido no metabolismo de auxinas, em particular no ácido indolacético (AIA) (FAQUIN, 2001).

Com incrementos na concentração do ácido bórico no meio de cultura, verificou-se um aumento de forma quadrática no número de folhas do porta-enxerto de videira, onde o maior número de folhas foi observado com concentração de 3,04 mg L-1 desse ácido.

Os dados obtidos aqui com esse porta-enxerto corroboram com Ribeiro (2005), que também observou que, plantas in vitro de Cattleya loddigesii possuíam menor número de folhas na ausência de sulfato de zinco hidratado adicionado ao meio de cultura Knudson. A redução dessa variável pode ter sido causada pela toxidez por sulfato de zinco.

Verificou-se interação significativa entre boro e zinco para número de folhas, comprimento da parte aérea e da raiz, e peso da matéria fresca da parte aérea de amoreirapreta. Não houve interação significativa para o número de raízes em relação à mudança da concentração dos micronutrientes do meio de cultura DSD1.

Com incrementos na concentração do ácido bórico no meio de cultura, observaram-se respostas antagônicas para as duas frutíferas estudadas, verificando uma diminuição de forma quadrática no número de folhas de amoreira-preta cv. Tupy, onde maior número foi observado na ausência dos micronutrientes estudados. Os dados obtidos para amoreira-preta corroboram com Ribeiro (2005), que também observou que, plantas in vitro de Cattleya loddigesii possuíam menor número de folhas na ausência de sulfato de zinco hidratado.

Resultados contrastantes foram obtidos por Franco (2004), que obteve maior número de folhas com a utilização de $17,2 \mathrm{mg} \mathrm{L}^{-1}$ de sulfato de zinco e $12,4 \mathrm{mg} \mathrm{L}^{-1}$ de ácido bórico do meio de cultura MS, na micropropagação de crisântemo (Dendranthema grandiflora). Entretanto, devese salientar que entre espécies as exigências nutricionais

Tabela 1 - Resumo da análise de variância para número de folhas (NF), comprimento da parte aérea (CPA), número de raízes (NR), peso fresco da parte aérea (PFPA) e comprimento das raízes (CR) do porta-enxerto de videira. UFLA, Lavras, 2006.

\begin{tabular}{ccccccc}
\hline Fontes de Variação & \multicolumn{5}{c}{ Quadrados Médios } \\
\cline { 2 - 7 } & GL & NF & CPA & NR & PFPA & CR \\
\hline B & 3 & $3,49^{*}$ & $0,79^{\text {n.s. }}$ & $0,041^{\text {n.s. }}$ & $0,00021^{\text {n.s. }}$ & $3,62^{*}$ \\
Zn & 3 & $1,66^{\text {n.s. }}$ & $4,47^{\text {n.s. }}$ & $0,0096^{\text {n.s. }}$ & $0,00069^{\text {n.s. }}$ & $2,49^{\text {n.s. }}$ \\
B x Zn & 9 & $1,08^{\text {n.s. }}$ & $1,33^{\text {n.s. }}$ & $0,0175^{\text {n.s. }}$ & $0,00053^{\text {n.s. }}$ & $1,63^{\text {n.s. }}$ \\
Resíduo & 45 & 0,76 & 2,56 & 0,0172 & 0,00035 & 1,23 \\
\hline CV $(\%)$ & 12,90 & 14,75 & 9,83 & 22,45 & 24,51 \\
\hline
\end{tabular}

* significativo a $5 \%$ de probabilidade.

Tabela 2 - Resumo da análise de variância para número de folhas (NF), comprimento da parte aérea (CPA), número de raízes (NR), peso fresco da parte aérea (PFPA) e comprimento das raízes (CR) de amoreira-preta. UFLA, Lavras, 2006.

\begin{tabular}{ccccccc}
\hline Fontes de Variação & \multicolumn{5}{c}{ Quadrados Médios } \\
\cline { 2 - 7 } & GL & NF & CPA & NR & PFPA & CR \\
\hline B & 3 & $68,35^{\text {n.s. }}$ & $1,234^{\text {n.s. }}$ & $0,137^{\text {n.s. }}$ & $0,0046^{\text {n.s. }}$ & $0,108^{\text {n.s. }}$ \\
Zn & 3 & $86,16^{\text {n.s. }}$ & $0,416^{\text {n.s. }}$ & $0,098^{\text {n.s. }}$ & $0,0058^{\text {n.s. }}$ & $0,174^{\text {n.s. }}$ \\
B x Zn & 9 & $60,46^{*}$ & $1,255^{*}$ & $0,056^{\text {n.s. }}$ & $0,0041^{*}$ & $0,349^{*}$ \\
Resíduo & 45 & 1,94 & 0,54 & 0,064 & 0,0012 & 0,066 \\
\hline CV $(\%)$ & 13,30 & 18,82 & 15,79 & 13,28 & 13,59 \\
\hline
\end{tabular}

* significativo a $5 \%$ de probabilidade. 
podem ser distintas. Portanto, possivelmente a amoreirapreta e o porta-enxerto de videira devem requerer um meio de cultura com menor concentração de boro para o desenvolvimento, quando comparados ao crisântemo.

Observa-se que incrementos de ácido bórico ao meio DSD1, em ausência de sulfato de zinco, proporcionaram diminuição no comprimento da parte aérea das brotações de amoreira-preta. Essa redução foi provavelmente causada por distúrbios nutricionais pela adição desses sais, sendo que o maior comprimento $(5,23$ $\mathrm{cm}$ ) foi observado com a ausência dos micronutrientes no meio de cultivo.

Franco (2004) trabalhando com micropropagação de crisântemo in vitro verificou que maior comprimento de plantas foi obtido em meio MS, adicionado de $17,2 \mathrm{mg} \mathrm{L}^{-1}$ de sulfato de zinco e 12,4 $\mathrm{mg} \mathrm{L}^{-1}$ ácido bórico, demonstrando a necessidade do aumento da disponibilidade desses nutrientes para o melhor crescimento das brotações.

Resultados semelhantes ao comprimento da parte aérea foram constatados para o peso da matéria fresca das brotações de amoreira-preta, ou seja, com incrementos nas concentrações de ácido bórico no meio DSD1, um decréscimo de forma quadrática no peso da matéria fresca da parte aérea foi também observado.

Ono et al. (1992) observaram que tratamentos com auxina mais boro obtiveram um aumento significativo da matéria fresca média de estacas de Camélia, em relação a tratamentos com apenas auxina, indicando a influência positiva do boro para o crescimento das brotações.

Pôde-se observar um decréscimo de forma quadrática no comprimento das raízes do porta-enxerto de videira com até $2,0 \mathrm{mg} \mathrm{L}^{-1}$ de ácido bórico e, a partir desse ponto, um ligeiro incremento do crescimento, atingindo-se 4,95 cm de comprimento com 4,0 $\mathrm{mg} \mathrm{L}^{-1} \mathrm{de}$ ácido bórico.

Resultados semelhantes foram verificados tanto na presença de 4,0 $\mathrm{mg} \mathrm{L}^{-1}$ da fonte de boro como na sua ausência. Se o objetivo do trabalho for o enraizamento de plantas e de reduzir custos, seria viável a utilização de um meio de cultura sem a presença de ácido bórico. Evidenciase assim que, para promover o comprimento médio do sistema radicular, o meio DSD1 é benéfico com apenas a adição de ácido bórico.

Segundo Jarvis (1983), a adição de boro proporcionou maior crescimento de raízes em estacas de feijão, uma vez que esse elemento é responsável pela formação de primórdios radiculares. De acordo com Pasqual (2001), o boro promove a destruição da auxina natural e aumenta sua translocação, logo, plantas com deficiência de boro têm sistema radicular reduzido.
Em substrato com deficiência de nutrientes, aumentar o comprimento das raízes é uma maneira da plântula obter os nutrientes necessários ao seu desenvolvimento mesmo que isso implique em maior gasto de reservas. Observou-se que a ausência dos dois micronutrientes, respectivamente, no meio de cultura DSD1 influenciou o comprimento médio do sistema radicular desta maneira.

Pôde-se observar também para a amoreira-preta, um decréscimo de forma quadrática em todas as variáveis analisadas e interação significativa sem a adição de boro e zinco no meio de cultura. A redução desses parâmetros pode ter sido causada pela toxidez por ácido bórico e/ou sulfato de zinco hidratado.

Se o objetivo do trabalho for de multiplicação de plantas e redução de custos, seria viável a utilização de um meio de cultura sem a presença desses micronutrientes. Evidencia-se assim que, para promover o comprimento da parte aérea e médio do sistema radicular, o meio DSD1 é benéfico na ausência de boro e zinco.

\section{CONCLUSÕES}

Melhores resultados na micropropagação de amoreira-preta cv. Tupy foram obtidos com a ausência de ácido bórico e de sulfato de zinco hidratado em meio de cultura DSD1.

Com 4,0 $\mathrm{mg} \mathrm{L}^{-1}$ de ácido bórico adicionado ao meio, verificou-se em média, maior número de folhas e comprimento das raízes do porta-enxerto de videira 'Kobber'.

\section{REFERÊNCIAS BIBLIOGRÁFICAS}

ANTUNES, L. E. C.; RASEIRA, M. C. B. Aspectos técnicos da cultura da amora-preta. Pelotas: Embrapa Clima Temperado, 2004. (Documentos, 122).

BROADLEY, M. R.; WHITE, P. S.; HAMMOND, J. P.; ZELKO, I.; LUX, A. Tansley review: zinc in plants. The New Phytologist, Lancaster, v. 173, p. 677-702, 2007.

CALDAS, L. S.; HARIDASAN, P.; FERREIRA, M. E. Meios nutritivos. In: TORRES, A. C.; CALDAS, L. S.; BUSO, J. A. (Eds.). Cultura de tecidos e transformação genética de plantas. Brasília, DF: Embrapa/CNPH, 1998. v. 1, p. $87-132$.

CHALFUN, N. N. J.; PASQUAL, M.; HOFFMANN, A. Fruticultura comercial: frutíferas de clima temperado. Lavras: UFLA-FAEPE, 1998. v. 7, 304 p. 
FERREIRA, D. F. Análises estatísticas por meio do Sisvar para Windows versão 4.0. In: REUNIÃO ANUAL DA REGIÃO BRASILEIRA DA SOCIEDADE INTERNACIONAL DE BIOMETRIA, 45., 2000, São Carlos. Anais... São Carlos: UFSCar, 2000. p. 255-258.

FAQUIN, V. Nutrição mineral de plantas. Lavras: UFLA/ FAEPE, 2001. 182 p.

FRANCO, J. C. C. Micropropagação do crisântemo: ácido bórico e sulfato de zinco. Lavras: UFLA, 2004. 21 p.

JARVIS, B. C. Auxin and boron in relation to the rooting response and ageing of mung bean cuttings. The New Phytologist, Lancaster, v. 95, p. 509-518, 1983.

KUPPER, A.; GARCIA, A. W. R.; MARTINS, M.; SANTINATO, R.; FERNANDES, D. R. Efeito do zinco, aplicado no solo em cobertura, na forma de sulfato e de óxido de zinco, sobre o cafeeiro: nota prévia. In: CONGRESSO BRASILEIRO DE PESQUISA CAFEEIRAS, 7., 1979, Araxá. Resumos... Rio de Janeiro: IBC/Gerca, 1979. p. 295-297.

MURASHIGE, T.; SKOOG, F. A. A revised medium for rapid growth and bioassays with tobacco tissue cultures. Physiologia Plantarum, Copenhagen, v. 15, p. 473-497, 1962.

NORBERTO, P. M.; REGINA, M. de A.; CHALFUN, N. N. J.; SOARES, A. M.; FERNANDES, V. B.; GAJEGO, E. B. Superfície foliar da videira 'Folha de Figo' e 'Niagara Rosada' conduzida em diferentes sistemas de condução. Ciência e Agrotecnologia, v.32, n.6, p. 1866-1871, 2008.

ONO, E. O.; RODRIGUES, J. D.; RODRIGUES, S. D. Interações entre auxinas e boro no enraizamento de estacas de camélia. Revista Brasileira de Fisiologia Vegetal, Campinas, v. 4, n. 2, p. 107-112, 1992.

PASQUAL, M. Meios de cultura. Lavras: UFLA/FAEPE, 2001. $74 \mathrm{p}$.

PASQUAL, M.; RAMOS, J. D.; HOFFMANN, A.; CARVALHO, G. R. Cultura de tecidos vegetais: tecnologia e aplicações: meios de cultura. Lavras: UFLA/ FAEPE, 1997. 127 p.

PEIXOTO, P. H. P.; PASQUAL, M. Influência da origem dos explantes na multiplicação e no enraizamento in vitro de porta-enxertos de videira. Ciência e Agrotecnologia, Lavras, v. 20, n. 3, p. 293 300, 1996.

RIBEIRO, L. de S. Adequação de meio de cultura para o crescimento in vitro de orquídeas do gênero Cattleya. 2005. Tese (Doutorado em Fisiologia Vegetal) - Universidade Federal de Lavras, Lavras, 2005.

SILVA, A. L.; DOAZAN, J. P. Une méthode d'irradiation aux rayons gamma appliquée à des porte-greffes de Vigne in vitro. Journal International Science of Vigne et Vin, v. 29, p. 1-9, 1995.

SKIRVIN, R. M.; CHU, M. C.; GOMEZ, E. In vitro propagation of Thornless trailing blackberries. HortScience, Alexandria, v. 16, n. 3, p. 310-312, 1981.

VILLA, F.; PASQUAL, M.; PIO, L. A. S.; TEODORO, G. S.; MIYATA, L. Y. Cloreto de potássio e fosfato de sódio na multiplicação in vitro de amoreira-preta cv. Tupy. Ciência e Agrotecnologia, v.32, n.1, p. 37-41, 2008. 